\title{
Hypotensive, vaso-relaxant, cardio-depressant and diuretic effect of crude extract of Crotalaria burhia (Fabaceae)
}

\author{
Muhammad Ali Raza, Imran Imran* \\ Department of Pharmacology, Faculty of Pharmacy, Bahauddin Zakariya University, Multan 60800, Pakistan \\ *For correspondence: Email: imran.ch@bzu.edu.pk; Tel: +92-321-6302819
}

Sent for review: 20 July 2019

Revised accepted: 27 January 2020

\begin{abstract}
Purpose: To examine 70 \% aqueous-methanol crude extract of Crotalaria burhia (Cb.Cr) for its hypotensive and diuretic effects.

Methods: The effect of intravenous administration of $\mathrm{Cb}$. Cr on blood pressure (BP) of normotensive anesthetized rats was studied. In vitro experiments on rabbit isolated aortic and atrial preparations were performed to elucidate the mechanism of action. The diuretic effect was assessed following oral administration of $\mathrm{Cb}$. $\mathrm{Cr}$ in rats.

Results: Intravenous administration of Cb.Cr produced 14.70 $\pm 1.21,22.00 \pm 2.24$ and $36.21 \pm 2.65 \%$ reduction in mean arterial blood pressure of the rats at doses of 1,3 and $10 \mathrm{mg} / \mathrm{kg}$, respectively. It was more potent in relaxing potassium (80 mM)- than phenylephrine $(1 \mu \mathrm{M})$-induced contractions in isolated aorta of rabbit with half-maximal effective concentration $\left(E C_{50}\right)$ values of $0.58 \pm 0.03$ and $1.58 \pm 0.16$ $\mathrm{mg} / \mathrm{mL}$, respectively, which are similar to verapamil. The extract showed depressant effects on spontaneously beating atrial preparations of rabbit in a dose-dependent manner. Moreover, Cb.Cr also increased urine volume and urinary electrolyte excretion in rats.

Conclusion: Crotalaria burhia crude extract exhibits hypotensive and diuretic effects in rats. The hypotensive activity of the extract possibly involves vasodilator, cardio-depressant, calcium channel blocking and diuretic actions.
\end{abstract}

Keywords: Khip, Crotalaria burhia, Calcium channel blocker, Antihypertensive, Diuretic

\begin{abstract}
This is an Open Access article that uses a fund-ing model which does not charge readers or their institutions for access and distributed under the terms of the Creative Commons Attribution License (http://creativecommons.org/licenses/by/4.0) and the Budapest Open Access Initiative (http://www.budapestopenaccessinitiative.org/read), which permit unrestricted use, distribution, and reproduction in any medium, provided the original work is properly credited.

Tropical Journal of Pharmaceutical Research is indexed by Science Citation Index (SciSearch), Scopus, International Pharmaceutical Abstract, Chemical Abstracts, Embase, Index Copernicus, EBSCO, African Index Medicus, JournalSeek, Journal Citation Reports/Science Edition, Directory of Open Access Journals (DOAJ), African Journal Online, Bioline International, Open-J-Gate and Pharmacy Abstracts
\end{abstract}

\section{INTRODUCTION}

Hypertension is a progressive pathological problem and causes serious health threat if left untreated. It is a critical cardiovascular risk factor in society and is a cause of most premature deaths in the world. It is thought to be a worldwide epidemic and a major predisposing factor for stroke, myocardial infarction, end-stage kidney disease and arteriosclerosis [1]. It has a very high mortality rate and is responsible for about 8 million deaths annually worldwide, out of which 1.5 million deaths occur in South East Asian region [2]. The National Health Survey of Pakistan poses a similar picture with about $18 \%$ of the adult population suffering from hypertension [3].

Hypertension is controlled by certain drugs with various mechanisms such as direct vasodilation, 
diuresis, calcium channel blockade, betareceptor blockade, rennin-angiotensin system blockade, alone or in combination, depending upon the situation. Every antihypertensive drug has its side effects like reduced renal function, fatigue, dry cough, angioedema, etc. Thus, alternative ways for its treatment may be considered. The combination of calcium channel blocker drug along with diuretic drug is the firstline treatment for hypertension [4].

Conventional antihypertensive therapy is a high cost therapy and is associated with many side effects. In developing countries of the World, more than $50 \%$ of population use herbal medicine because of lesser side effects and better acceptability. Several ethnobotanical studies in recent years revealed that hundreds of plants are used for treating hypertension empirically. The use of natural medicinal agents like plants is as old as human civilization [4-6]. The socio-economic status of rural parts of developing countries contributes a lot to this usage and leads to an increased search of plants with good medicinal properties. The main benefits of using these natural agents are ease of availability, fewer side effects and costeffectiveness [6].

Crotalaria genus of Fabaceae family is distributed all over the world in tropical and subtropical areas and comprises of approximately 700 species. Crotalaria burhia Buch.-Ham, known locally as Khip, is a fibrous plant belonging to this family. It is commonly found in arid parts of Pakistan, Afghanistan, and India [7]. Preliminary phytochemical investigations disclosed that the plant contains glycosides, alkaloids, flavonoids like quercetin, saponins, and steroids like $\beta$-sitosterol [8]. In ancient Ayurvedic medicine, the plant is used for the treatment of several disorders. The whole plants as well as its parts such as leaves, branches, stem and roots are used separately for the treatment of different diseases. For example, leaves and branches are used as cooling medicine, fresh plant juice is applied on eczema, whole plant is used in gout, kidney disorders, swelling, pain, tumor and hydrophobia. Extract of root added with sugar is used for the treatment of chronic kidney pain. The root decoction is used in the treatment of typhoid [9]. Whole plant extract is reported to be used in the treatment of hypertension [10].

The literature search revealed that Crotalaria burhia has not been reported for scientific justification of its traditional medicinal uses in cardiovascular disorders and as diuretic. Therefore, the present study was aimed to investigate possible hypotensive and diuretic effects of $\mathrm{Cb} . \mathrm{Cr}$ in animal models.

\section{EXPERIMENTAL}

\section{Plant material}

Whole plant of Crotalaria burhia Buch. -Ham was collected from the desert of Cholistan, Punjab, Pakistan in the months of March and April 2016. It was authenticated by Dr. Zafar Ullah, Department of Botany, Bahauddin Zakariya University, Multan and a voucher specimen kept in the departmental herbarium (token no. FI-PK50-4). The plant material was shade-dried for two weeks and made free from any foreign matter. Then it was subjected to grinding to make coarse powder utilizing an electric grinder.

\section{Preparation of extract}

The powder material of plant was immersed in an aqueous-methanol solvent mixture $(30: 70 \mathrm{v} / \mathrm{v})$ and kept for three days at room temperature. The mixture was first filtered with cotton cloth followed by Whatmann filter paper 1 . The same process was repeated thrice using the residue of plant material and fresh solvent mixture. The three filtrates were then mixed and subjected to evaporation using rotary evaporator at $45 \pm 1^{\circ} \mathrm{C}$. At the end of this process, thick viscous dark brown color mass was obtained [11]. The extract was then kept at low temperature $\left(-4^{\circ} \mathrm{C}\right)$ for further use. The percent yield of crude extract was $10.3 \%$. For oral administration, this extract was dissolved in sodium chloride solution $(0.9 \%)$. For intravenous use, it was dissolved in sodium chloride solution $(0.9 \%)$ containing $(5 \%)$ DMSO. Furthermore, for in vitro experimentation, stock solution $(300 \mathrm{mg} / \mathrm{mL})$ of crude extract was made by dissolving it in double distilled water containing (10\%) DMSO, from which further dilutions were made in distilled water.

\section{Animals}

Locally available breed of Albino rabbits (male and female) weighing $1.0-1.5 \mathrm{~kg}$ and SpragueDawley rats (male and female) weighing approximately $200-250 \mathrm{~g}$ were employed in the current study. All animals were housed in controlled environment at $25 \pm 3^{\circ} \mathrm{C}$ and exposed to twelve hours of light-dark cycles. The fresh water and standard diet were freely available to the animals.

\section{Ethical issue}

The ethical committee of the institution approved the study (approval no. PhDL-03) and is 
complied with the "Guide for the Care and Use of Laboratory Animals" provided by the Institute of Laboratory Animal Research, Commission on Life Sciences, National Research Council [12].

\section{Drugs and chemicals}

The drugs utilized in present study were injection valium (manufactured by Roche Pharmaceuticals, Karachi), injection ketalar (manufactured by Akahai Pharmaceuticals, Karachi), injection heparol (manufactured by China) and injection adrenaline (manufactured by PDH Pharmaceuticals, Lahore). Research grade chemicals were used in this study and were diluted in double-distilled water before use.

\section{Measurement of hypotensive effect of $\mathrm{Cb} . \mathrm{Cr}$ in rats}

The albino rat was anesthetized with the help of intraperitoneal injection of ketamine (80-50 $\mathrm{mg} / \mathrm{kg}$ ) and diazepam (5 mg/kg). On the dissecting table, the animal was fixed in supine position and an electric lamp was adjusted in a position to maintain body temperature of the rat. A minor incision was given to expose the left jugular vein, right carotid artery and trachea. To facilitate spontaneous respiration, a polyethylene (PE-50) tube was catheterized into the trachea. $0.1 \mathrm{~mL}$ drugs followed by $0.1 \mathrm{~mL}$ saline were administered intravenously through the jugular vein.

Blood pressure was monitored continuously through BP transducer connected to the carotid artery. Between the administrations of respective drugs, blood pressure was permitted to return to its basal values. Change in BP was calculated as a percent difference from basal value immediately before dose to lowest value after the dose. Before administering the injections of studied extract, control responses of adrenaline $(1 \mu \mathrm{g} / \mathrm{kg})$ and acetylcholine $(1 \mu \mathrm{g} / \mathrm{kg})$ were obtained. By adding $1 / 3$ of pulse pressure to diastolic blood pressure, Mean arterial blood pressure (MABP) was calculated [11].

\section{In vitro studies on isolated aorta and atria of rabbit}

The effects of the extract were directly observed on isolated aorta and atria from rabbits. Animals were euthanized and their thoracic aorta was removed, cleaned and cut into $2-3 \mathrm{~mm}$ wide rings to be used for the study. These aortic rings were separately mounted in a $15 \mathrm{~mL}$ organ bath, which was filled with solution of Krebs-Henseleit with $\mathrm{pH} 7.4$ and maintained at $37^{\circ} \mathrm{C}$. A preload tension $(2 \mathrm{~g})$ was given to the studied aortic ring and contractions were measured using an isometric transducer system connected with a PowerLab data acquisition system. One $h$ equilibration period was given to the preparations which were stabilized by giving repeated treatments with sub-maximal doses $(0.3 \mu \mathrm{M})$ of phenylephrine. Vasodilator effects of the studied extract were then observed by adding it or the standard drug in increasing doses and in a cumulative manner on aortic rings which were formerly contracted with either potassium (80 $\mathrm{mM})$ or phenylephrine $(1 \mu \mathrm{M})$.

Paired atria were quickly and carefully separated from ventricles of the isolated heart of rabbit and paired atrial preparation was mounted in an organ bath filled with the solution of KrebsHenseleit at $34^{\circ} \mathrm{C}$, which was constantly gassed with a mixture of carbon dioxide and oxygen. Rate and force of atrial beatings were measured at preload tension of $1 \mathrm{~g}$ via force displacement transducer attached with the PowerLab data acquisition system. Before addition of any drug, 30 min time was given to equilibrate the tissue preparation, while fluid changes were made at 10 min intervals during the said time. After the addition of studied extract in cumulative dosing manner, percentage changes in rate and force of baseline contractions were calculated [13].

\section{Diuretic assay}

Sprague-Dawley rats (male and female) utilized in the current study were kept on fasting for $12 \mathrm{~h}$ before the experimentation but water was freely available to them during this period. Each rat was given sodium chloride solution orally $(0.9 \%, 20$ $\mathrm{ml} / \mathrm{kg}$ ) to induce hydration and saline load. After half an hour, five groups of rats were made, each comprising of six rats. Sodium chloride solution $(0.9 \%, 10 \mathrm{ml} / \mathrm{kg})$ was given orally to the control group. The $2^{\text {nd }}$ group received furosemide (20 $\mathrm{mg} / 10 \mathrm{ml} / \mathrm{kg}$ ), orally. The plant extract was given orally to the study groups at different doses. Immediately, after giving oral doses, rats were placed in diuretic cages separately. Urine of the animals was collected for $6 \mathrm{~h}$ to determine its total volume. Moreover, urinary concentrations of potassium and sodium were measured by flame photometer (manufactured by Sherwood Scientific Ltd, UK, Model 410C) and a commercial kit (Chloride, DiaSys Diagnostic, Germany) was used to measure chloride concentration [14].

\section{Statistical analysis}

Data are expressed as half maximal effective concentrations $\left(E_{50}\right)$ with a $95 \%$ confidence interval $(\mathrm{Cl})$ and as mean \pm standard error of the 
mean (SEM). For the analysis and construction of graphs, GraphPad Prism was employed. The comparison of different groups was made by applying statistical tool ANOVA followed by Dunnett's test. Values of $p<0.05$ were taken as statistically significant.

\section{RESULTS}

\section{Hypotensive effect of $\mathrm{Cb} . \mathrm{Cr}$ in rats}

The baseline mean arterial blood pressure (MABP) of normotensive anesthetized rats was $108.46 \pm 4.86(n=5)$. Intravenous administration of solvent alone did not produce significant changes in the MABP of rats from baseline values (data not shown). The results revealed that intravenous administration of $\mathrm{Cb}$. Cr caused $14.70 \pm 1.21,22.00 \pm 2.24$ and $36.21 \pm 2.65 \%$ reductions in MABP at doses of 1,3 and 10 $\mathrm{mg} / \mathrm{kg}$, respectively (Figure 1). Verapamil (1 $\mathrm{mg} / \mathrm{kg}$, i.v.) resulted in $52.45 \pm 2.43 \%$ decrease, and acetylcholine $(1 \mu \mathrm{g} / \mathrm{kg}$, i.v.) caused $55.80 \pm$ $1.87 \%$ fall in MABP of anesthetized rats from baseline values. Atropine pretreatment $(1 \mathrm{mg} / \mathrm{kg})$ eliminated the BP lowering effect of acetylcholine. In contrast, atropine pretreatment did not influence the hypotensive effect of verapamil or $\mathrm{Cb} . \mathrm{Cr}$ (Figure 2).

\section{Direct vasodilator effect and possible mode of action of $\mathrm{Cb} . \mathrm{Cr}$}

Isolated aortic rings of rabbits were employed for studying the direct vasodilatory effect of $\mathrm{Cb}$. $\mathrm{Cr}$ and its possible mechanism of action. The crude extract of Crotalaria burhia (Cb.Cr) relaxed the contractions induced by potassium $(80 \mathrm{mM})$ and phenylephrine $(1 \mu \mathrm{M})$ with $\mathrm{EC}_{50}$ values of $0.58 \pm$ 0.03 and $1.58 \pm 0.16 \mathrm{mg} / \mathrm{mL}$, respectively, in a dose-dependent manner (Figures 3, Figure 4 A). The standard calcium channel blocker and vasodilator drug, verapamil, also relaxed potassium $(80 \mathrm{mM})$ and phenylephrine $(1 \mu \mathrm{M})$ induced contractions with $\mathrm{EC}_{50}$ values of 0.4981 \pm 0.062 and $1.37 \pm 0.128 \mu \mathrm{M}$, respectively, in a dose-dependent manner, which shows that it is more potent against potassium than phenylephrine-induced contractions as shown in Figure $4 \mathrm{~B}$.

Moreover, $\mathrm{Cb} . \mathrm{Cr}$ caused a little decrease in the force of contraction and heart rate when tested on spontaneously contracting rabbit paired atria at concentrations varying from 0.01 to 0.1 $\mathrm{mg} / \mathrm{mL}$. When the concentration was further increased $(0.3$ to $5.0 \mathrm{mg} / \mathrm{mL}$ ) it caused more pronounced decreases in force and rate of spontaneous contractions as shown in Figure 5.

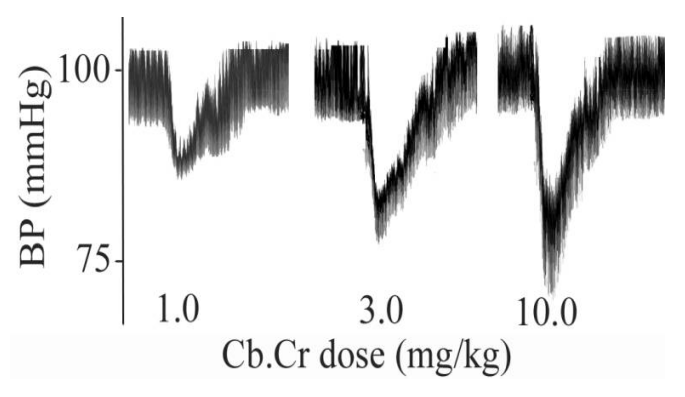

Figure 1: Record showing the effect of administration of different doses of Crotalaria buriha crude extract on blood pressure of anesthetized rats

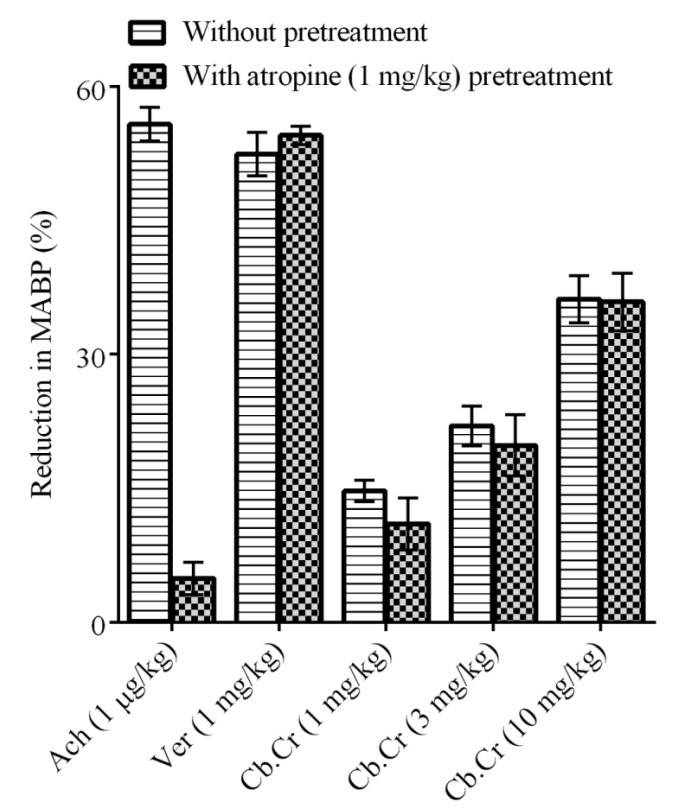

Figure 2: Effects of verapamil (Ver), acetylcholine (Ach) and increasing doses of Crotalaria buriha crude extract (Cb.Cr) on mean arterial blood pressure (MABP) of anesthetized rats, with or without atropine pretreatment. Values shown are mean \pm SEM of 5 determinations

(A)

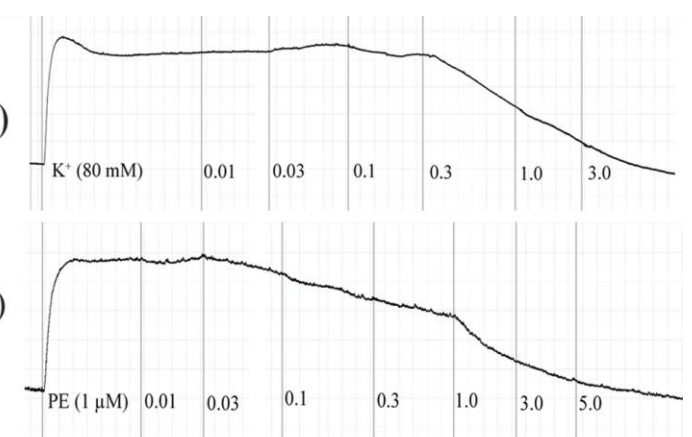

Cb.Cr. concentration $\mathrm{mg} / \mathrm{ml}$

Figure 3: Effects of Crotalaria buriha crude extract against contractions induced by $(\mathrm{A})$ potassium $\left(\mathrm{K}^{+}, 80\right.$ $\mathrm{mM})$ and $(\mathrm{B})$ phenylephrine $(\mathrm{PE}, 1 \mu \mathrm{M})$ in isolated aortic preparations of rabbit. Vertical lines indicate the point of administration of the contractile or test material 
(A)

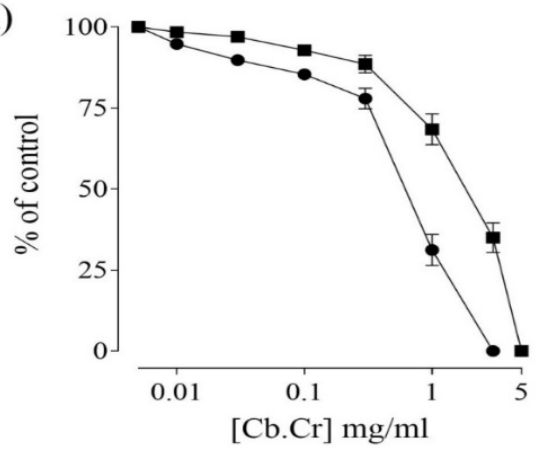

(B)

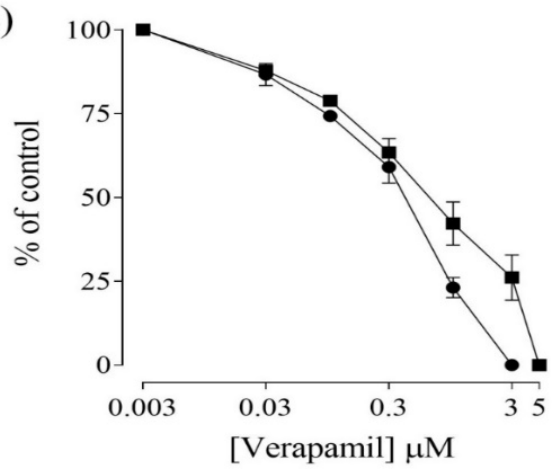

Figure 4: Effects of (A) crude extract of Crotalaria burhia (Cb.Cr), and (B) verapamil on (-) phenylephrine $(\mathrm{PE}, 1 \mu \mathrm{M})$ and $(\bullet)$ potassium $\left(\mathrm{K}^{+}, 80\right.$ $\mathrm{mM}$ ) -induced contractions in the isolated aortic preparations of rabbit.Values shown are mean \pm SEM $(\mathrm{n}=5)$

\section{Effect of $\mathrm{Cb} . \mathrm{Cr}$ on urinary volume}

Results revealed that following oral administration of $\mathrm{Cb} . \mathrm{Cr}(100,300$ and 500 $\mathrm{mg} / \mathrm{kg}$ ) and furosemide (20 mg/kg), there was increased urine volume per $100 \mathrm{~g}$ of body weight of the animals after $6 \mathrm{~h}$, when compared with the control group treated with sodium chloride solution $(0.9 \%, 10 \mathrm{~mL} / \mathrm{kg})$ as shown in Table 1 .

\section{Effect of $\mathrm{Cb} . \mathrm{Cr}$ on urinary electrolyte excretion}

The urinary electrolytes (sodium, potassium and chloride) excretion by animals in various groups are presented in Table 2. Results revealed that oral treatments of animals with $\mathrm{Cb} . \mathrm{Cr}$ at doses 100,300 and $500 \mathrm{mg} / \mathrm{kg}$ caused an increased electrolyte excretion in the urine $(p<0.05)$, as compared with the control group.

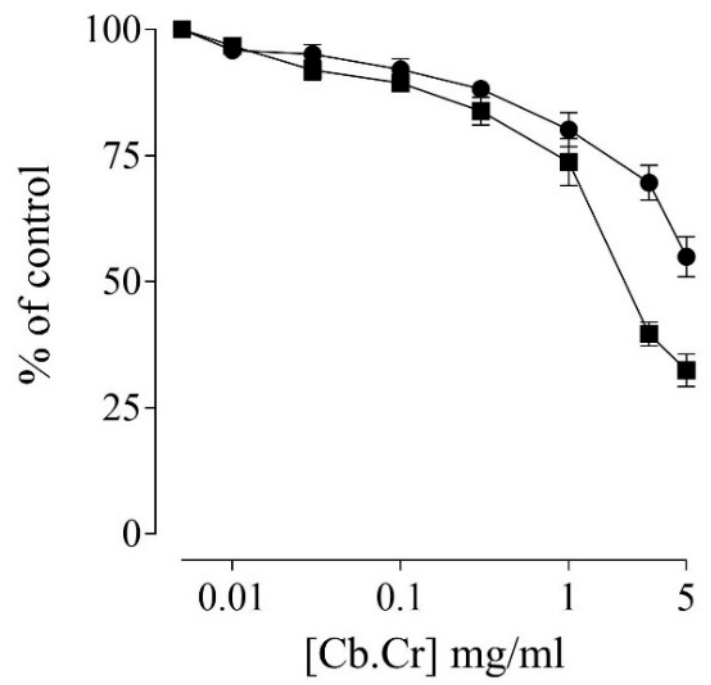

Figure 5: Effect of crude extract of Crotalaria burhia (Cb.Cr) on rate $(\bullet)$ and force ( $\bullet$ ) of contraction of the isolated paired atrial preparations of rabbit. Values shown are mean \pm SEM $(n=5)$

Table 1: Mean urine volume collected after $6 \mathrm{~h}$ in various groups of rats receiving normal saline, different doses of Crotalaria burhia (Cb.Cr) and standard drug furosemide

\begin{tabular}{lcc}
\hline Group & $\begin{array}{c}\text { Dosage } \\
(\mathbf{m L} / \mathbf{k g})\end{array}$ & $\begin{array}{c}\text { Urine volume }(\mathbf{m l} / \mathbf{1 0 0} \\
\mathbf{g} / \mathbf{6 ~ h})\end{array}$ \\
\hline Normal saline & 10 & $1.58 \pm 0.14$ \\
Furosemide & 20 & $5.93 \pm 0.40^{\cdots}$ \\
Cb.Cr 1 & 100 & $3.16 \pm 0.26^{*}$ \\
Cb.Cr 2 & 300 & $4.32 \pm 0.57^{* *}$ \\
Cb.Cr 3 & 500 & $4.60 \pm 0.35^{* * *}$ \\
\hline Values shown are mean \pm SEM; ${ }^{* *} p<0.05,{ }^{* *} p<0.01$, \\
\end{tabular}

Table 2: Urinary electrolyte excretion in rats following treatment with normal saline, different doses of Crotalaria burhia (Cb.Cr) and standard drug furosemide

\begin{tabular}{|c|c|c|c|c|c|}
\hline $\begin{array}{c}\text { Treatment group } \\
\text { (dose) }\end{array}$ & $\mathrm{Na}^{+}$ & $\begin{array}{c}\mathrm{K}^{+} \\
(\mu \mathrm{mol} / 100 \mathrm{~g} / 6 \mathrm{~h})\end{array}$ & $\mathrm{Cl}^{-}$ & $\mathrm{Na}^{+} / \mathrm{K}^{+}$ & $\begin{array}{c}\text { Ion } \\
\text { quotient }\end{array}$ \\
\hline $\begin{array}{l}\text { Normal saline } \\
(10 \mathrm{~mL} / \mathrm{kg})\end{array}$ & $130.20 \pm 6.44$ & $7.78 \pm 0.23$ & $127.50 \pm 2.20$ & 16.73 & 0.92 \\
\hline $\begin{array}{l}\text { Furosemide } \\
(20 \mathrm{mg} / \mathrm{kg})\end{array}$ & $374.00 \pm 7.94^{\star \star \star}$ & $31.42 \pm 0.58^{\star \star \star}$ & $516.50 \pm 9.38^{\star \star \star}$ & 11.90 & 1.27 \\
\hline $\mathrm{Cb} . \mathrm{Cr}(100 \mathrm{mg} / \mathrm{kg})$ & $163.40 \pm 5.29$ & $10.02 \pm 0.07^{\ldots}$ & $157.70 \pm 2.20^{\circ}$ & 16.30 & 0.91 \\
\hline Cb.Cr (300 mg/kg) & $193.40 \pm 2.54 \cong$ & $13.78 \pm 0.23^{\cdots}$ & $219.80 \pm 5.52 \cdots$ & 14.03 & 1.06 \\
\hline Cb.Cr (500 mg/kg) & $222.20 \pm 4.62 "$ & $23.22 \pm 0.31^{\prime \prime}$ & $359.00 \pm 10.9^{\prime \prime}$ & 9.56 & 1.46 \\
\hline
\end{tabular}

lon quotient $=\mathrm{Cl} /\left(\mathrm{Na}^{+}+K^{+}\right)$. Values are mean \pm SEM $(n=6) ;{ }^{*} p<0.05,{ }^{* *} p<0.01, p<0.001$ 


\section{DISCUSSION}

The present study describes the hypotensive and diuretic potential of $\mathrm{Cb}$.Cr. Diuretic drugs can be utilized to adjust the composition and volume of body fluids in various pathological conditions like hypertension. In hypertension, diuretic drugs decrease cardiac output by decreasing arterial resistance and blood volume [15]. Blood pressure is the result of peripheral resistance and cardiac output [16]. Therefore, the lowering of BP might be due to one of these factors. A number of botanical extracts cause reduction in $\mathrm{BP}$ by the stimulation of muscarinic receptors [12], and the underlying mechanism for this hypotensive effect is the endothelium NOdependent vasodilatory and cardio-depressant actions [17].

In the current study, the blockade of muscarinic receptors by atropine, which is a non-specific muscarinic receptor blocker, antagonized the BP lowering effect of acetylcholine and did not affect the BP lowering effect of $\mathrm{Cb} . \mathrm{Cr}$ and verapamil. The result of present study eliminates possibility of muscarinic receptors involvement in BP lowering effect of the extract, and suggests that the decrease in MABP of anesthetized normotensive rats by the $\mathrm{Cb} . \mathrm{Cr}$ is due to the mechanism similar to verpamail, which blocks calcium channels.

Vasorelaxant drugs are used in hypertension. In the present study, the vasorelaxant effect of $\mathrm{Cb} . \mathrm{Cr}$ was evaluated using phenylephrine and potassium contracted animal aorta. Depolarization of cell membrane by Potassium $(80 \mathrm{mM})$ results in influx of extracellular calcium by activating voltage-dependent calcium channels. It causes sustained contractions due to increased free cytosolic calcium. On the other hand, phenylephrine, via activation of $\alpha$ adrenergic receptors, is responsible for the formation of inositol 1,4,5- trisphosphate $\left(\mathrm{IP}_{3}\right)$ from phosphatidylinositol (PI). Owing to this conversion, there is increased calcium release from intracellular stores and influx via voltagedependent calcium channels which lead to the contraction of the aorta [18]. Crotalaria burhia crude extract, was more potent in relaxing potassium $(80 \mathrm{mM})$ than phenylephrine $(1 \mu \mathrm{M})$ induced contraction in aorta, proposing that $\mathrm{Cb} . \mathrm{Cr}$ may be acting via voltage-dependent Calcium channels. Calcium channel blocking drugs belong to a group of antihypertensive drugs, which owing to their cardio-depressant and vasodilator properties are widely used for the management of hypertension and angina pectoris [19].
Crotalaria burhia crude extract decreased heart rate and force of contraction of spontaneously contracting paired atria of rabbit. These negative inotropic and chronotropic effects by $\mathrm{Cb}$.Cr might be due to Calcium channel blocking effect [20].

Diuretic drugs are extensively used for the management of various disorders of urinary and cardiovascular systems. These agents use different mechanisms for diuresis, out of which four main are carbonic anhydrase inhibition, aldosterone antagonism (potassium-sparing), inhibition of $\mathrm{Na}^{+}, \mathrm{K}^{+}$and $\mathrm{Cl}^{-}$co-transport (loop diuretics) and inhibition of $\mathrm{Na}^{+}$and $\mathrm{Cl}^{-}$cotransport $[15,21]$. Crotalaria burhia crude extract caused a dose-dependent increase in urinary output and urinary electrolyte excretion. Urinary electrolytes and their ratios are very important for the determination of diuretic mechanism of test materials [22]. The high $\mathrm{Na}^{+} / \mathrm{K}^{+}$ratio in urine suggests both potassium sparing and natriuretic effects. Like standard loop diuretic drug, furosemide, $\mathrm{Cb} . \mathrm{Cr}$ decreased $\mathrm{Na}^{+} / \mathrm{K}^{+}$ratio thus excluding the possibility of potassium-sparing effect. Moreover, ion quotient $\left[\mathrm{Cl}^{-} /\left(\mathrm{Na}^{+}+\mathrm{K}^{+}\right)\right]$gives a basis for carbonic anhydrase activity, whose value below 0.8 indicates carbonic anhydrase inhibitory activity $[22,23]$.

Crotalaria burhia crude extract showed ion quotient values greater than 0.8 at all the tested doses, thus eliminating possible carbonic anhydrase inhibitory mechanism in the diuretic effect of the extract. Loop diuretics induce increased diuresis and electrolyte excretion via $\mathrm{Na}^{+} / \mathrm{K}^{+} / \mathrm{Cl}^{-}$co-transport inhibition (at the thick ascending loop of Henle), whereas thiazide diuretics act via $\mathrm{Na}^{+} / \mathrm{Cl}^{-}$co-transport (at distal convoluted tubules) [2]. Hence, the present study suggests that the underlying mechanism of this diuretic effect may be thiazide and loop diuretic like.

The results of the diuretic effect of $\mathrm{Cb} . \mathrm{Cr}$ are in agreement with its folklore Ayurvedic use as a diuretic and for chronic kidney pain [24]. It has been well established that the presence of various phytochemical constituents like organic acids, saponins and glycosides along with phenolic compounds contribute to the diuretic effect of the plant extracts [25]. The diuretic effect of $\mathrm{Cb} . \mathrm{Cr}$ is comparable with the standard diuretic drug, furosemide, which may be due to phytochemical compounds present in Crotalaria burhia [8].

\section{CONCLUSION}

The findings of this study demonstrate that $\mathrm{Cb} . \mathrm{Cr}$ possesses blood pressure-lowering and diuretic 
effects in animal models. The hpotensive effect of the plant extract involves vasodilatory and cardiodepressent actions, possibily mediated via the mechanim of calcium channel blockade. Thus, the study justifies the traditional uses of Crotalaria burhia crude extract as a hypotensive and diuretic drug.

\section{DECLARATIONS}

\section{Acknowledgement}

The authors are thankful to the Head of Pharmacology Department, Bahauddin Zakariya University, Multan, Pakistan for giving all the required research facilities.

\section{Conflict of interest}

No conflict of interest is associated with this work.

\section{Contribution of authors}

We declare that this work was done by the authors named in this article and all liabilities pertaining to claims relating to the content of this article will be borne by the authors. Imran conceived and designed the study. Muhammad Ali Raza collected and analyzed data and wrote the manuscript. Both authors have read and approved the manuscript for publication.

\section{Open Access}

This is an Open Access article that uses a funding model which does not charge readers or their institutions for access and distributed under the terms of the Creative Commons Attribution License (http://creativecommons.org/licenses/by/ 4.0) and the Budapest Open Access Initiative (http://www.budapestopenaccessinitiative.org/rea d), which permit unrestricted use, distribution, and reproduction in any medium, provided the original work is properly credited.

\section{REFERENCES}

1. Cienfuegos-Jovellanos E, Quiñones MM, Muguerza B, Moulay L, Miguel M, Aleixandre A. Antihypertensive effect of a polyphenol-rich cocoa powder industrially processed to preserve the original flavonoids of the cocoa beans. J Agric Food Chem 2009; 57: 6156-6162.

2. Hypertension [homepage on internet]. World Health Organization in Southeast Asia [cited 2018 Feb 15]. Available from http://www.searo.who.int/topics/hypertension/en/
3. Saleem F, Hassali $A A$, Shafie $A A$. Hypertension in Pakistan: time to take some serious action. $\mathrm{Br} J$ Gen Pract 2010; 60: 449-450.

4. Landazuri $P$, Chamorro NL, Cortes BR. Medicinal plants used in the management hypertension. J Anal Pharm Res 2017; 5: 00134.

5. Baharvand-Ahmadi B, Bahmani M, Tajeddini P, RafieianKopaei M, Naghdi N. An ethnobotanical study of medicinal plants administered for the treatment of hypertension. J Renal Inj Prev 2016; 5: 123-128.

6. Rates SM. Plants as source of drugs. Toxicon 2001; 39: 603-613.

7. Saboon, Bibi, Y, Arshad M, Ahmad N, Riaz I, Chaudhari SK. An insight into medicinal and ethnopharmacological potential of Crotalaria burhia. Asian Pac J Trop Dis 2015; 5: 511-514.

8. Kataria S, Shrivastava $B$, Khajuria RK, Suri KA, Sharma $P$. Pharmacognostic evaluation of Crotalaria burhia buch.Ham. Indian J Tradit Know 2011; 10: 629-635.

9. Talaviya PA, Vyas BM, Sharma $D$, Indoria SP, Suman RK. Anti-inflammatory activity of four fractions of ethanolic extract of Crotalaria burhia Buch.-Ham. root in rats. Natl J Physiol Pharm Pharmacol 2014; 4(3): 213217.

10. Ozturk $M$, Altay V, Latiff, Shareef $S$, Shaheen $F$, Choudhary MI. Potential medicinal plants used in the hypertension in Turkey, Pakistan, and Malaysia. In: Ozturk M, Hakeem KR, editors. Plant and human health, volume 1. Switzerland: Springer Cham; 2018. p. 595618.

11. Jabeen Q, Bashir S, Lyoussi B, Gilani AH. Coriander fruit exhibits gut modulatory, blood pressure lowering and diuretic activities. J Ethnopharmacol 2009; 122:123-130.

12. National Research Council, Guide for the care and use of laboratory animals, 8th edition. Washington: National Academics Press; 2011.

13. Janbaz KH, Hamid I, Mahmood M, Gilani $A H$. Bronchodilator, cardiotonic and spasmolytic activities of the stem barks of Terminalia arjuna. Can J App Sci 2011; 3: 104-120.

14. Chen $D Q$, Feng $Y L$, Tian $T$, Chen $H$, Yin L, Zhao $Y Y$, Lin RC. Diuretic and anti-diuretic activities of fractions of Alismatis rhizoma. J Ethnopharmacol 2014; 157: 114118.

15. Shah SU, Anjum S, Littler LA. Use of diuretics in cardiovascular diseases: (2) hypertension. Postgrad Med J 2004; 80: 271-276.

16. Mayet J, Hughes A. Cardiac and vascular pathophysiology in hypertension. Heart 2003; 89: 11041109.

17. Van-Zwieten PA, Doods HN. Muscarinic receptors and drugs in cardiovascular medicine. Cardiovas Drugs Ther 1995; 9: 159-167.

18. Karaki H, Ozaki H, Hori M, Mitsui-Saito M, Amano Kl, Harada K, Miyamoto S, Nakazawa H, Won K, Sato K. Calcium movements, distribution, and functions in smooth muscle. Pharmacol Rev 1997; 49: 157-230. 
19. Eisenberg MJ, Brox A, Bestawros AN. Calcium channel blockers: an update. Am J Med 2004; 116: 35-43.

20. Aslam N, Janbaz KH, Jabeen Q. Hypotensive and diuretic activities of aqueous-ethanol extract of Asphodelus tenuifolius. Bangladesh J Pharmacol 2016; 11: 830-837.

21. Shah SU, Anjum S, Littler WA. Use of diuretics in cardiovascular diseases: (1) heart failure. Postgrad Med J 2004; 80: 201-205.

22. Ansari MN, Ganaie MA, Khan TH, Samad A, Madkhali $H A$, Ahamad SR. Evaluation of diuretic potentials of naringenin in hypercholesterlemic rats. Trop $J$ Pharm Res 2018; 17: 239-244.

23. Vogel HG. Drug discovery and evaluation: pharmacological assays. Germany: Springer-Verlag; 2002. p. 324-325.

24. Katewa S, Galav P. Additions to the traditional folk herbal medicines from Shekhawati region of Rajasthan. Indian J Tradit Knowl 2006; 4: 237-245.

25. Kalinina $S A$, Elkina $O V$, Kalinin DV, Syropyatov $B Y$, Dolzhenko AV. Diuretic activity and toxicity of some Verbascum nigrum extracts and fractions. Pharm Biol 2014; 52: 191-198. 